\title{
Network Optimization of Solid Wastes Management in Chennai, India: case study
}

\author{
Sanjeevi $\mathrm{V}^{\mathrm{a}^{*}}$, Shahabudeen $\mathrm{P}^{\mathrm{b}}$ \\ ${ }^{a}$ Director, Vellore Institute of Technology (VIT), Katpadi Road, Vellore, Tamil Nadu, 632014. India \\ ${ }^{b}$ Department of Industrial Engineering, College of Engineering, Anna University, Sardar Patel Road, Guindy, \\ Chennai 600025. India
}

\begin{abstract}
The purpose of this research is to present the current status of solid wastes flow in Chennai and optimize the cost of handling solid wastes. The city limits was extended form $175 \mathrm{~km}^{2}$ to $426 \mathrm{~km}^{2}$ in 2011 , leading to sub optimum levels in solid waste management of 4840 tons per day. There is also pressure on city managers to reduce the cost of transport of solid wastes, due to shrinking budgetary allocations. In the changed scenario, there is need to examine the need for the current 12 transfer stations (TS) and also routing of solid waste transport vehicles. The existing TSs was set up historically without taking into account optimality. A linear programming model was developed to arrive at eight optimal transfer stations. The implementation of the proposal will bring in an annual saving of US\$ 3.52 Million, about 33.1 percent of the analyzed transport, space and handling cost.

Keywords: integrated solid waste management, transfer stations, optimal locations, handling costs, linear programming and Chennai Optimal Transfer Stations for Integrated Solid Wastes Management in Chennai Metropolitan Area, India
\end{abstract}

\section{Introduction}

Worldwide, 120 to 130 billion tons of natural resources are consumed every year and 4 billion tons of municipal solid wastes (MSW) are generated as well (Chalmin and Gaillochet, 2009). An amount of US\$ 410 billion per year is spent from collection to recycling of solid waste (SW). The SW per year in India is likely to reach 260 million tons by 2047, which is more than 5 times of the current level (Essaku et al., 2007). With shrinking budgets for various city managements across the world, the mission is to increase the collection of waste with least cost (Rogoff et al., 2004). Currently most of the Solid Waste management (SWM) is being carried out using open cycle waste management systems, instead of closed cycle systems (Hina Zia and Devadas, 2008). Rapid paced and unplanned industrialization, population growth, increase in the living standards of the population, and technological developments been adding to the woes of solid wastes management issues in cities across the world. The urban population in India is up from 300 million in 2001 to 395 million in 2011 (Katkar, 2012). The trend is almost the same in all developing countries. According to the State of the World Cities Report of the UN-HABITAT (UN-HABITAT, 2010a, 2010b), more than 70 per cent of the global GDP comes from cities.Failure of the Integrated Solid Waste Management (ISWM) could jeopardize public health. Solid wastes contaminate groundwater as well as surface water and increases air pollutants, leading to miserable living conditions. This put enormous pressure on the research, academic and administrative systems of city managements. There is an urgent need to look in to the issues of ISWM and also improve the ability of city administrators to manage ISWM with the least cost. Transport cost alone comes to more than 50 per cent of the total costs incurred in ISWM in major cities of the developed world. However, in the developing countries (Ghose et al., 2006), about 85 per cent of the total costs is being spent on collection and transport. In Corporation of Chennai, the SW collection and road sweeping cost (mostly manual) comes to 62 percent and transport cost is 22 per cent of the total SWM costs (Annual Budget of the Corporation of Chennai, 2014-15).In the present research, for minimizing the transport and handling costs of SWM, the authors apply Linear Programming for optimization of the number of transfer stations for the entire city.

\section{Research on optimization models}

According to Komilis (2008), there are fundamentally three nodes in SWM systems, namely, the generation node, the intermediate node and the sink node. As per the USEPA (1977), the setting up of intermediate nodes or Transfer Stations (TS) become viable when the distance between the generation nodes (City Wards) and the sink nodes or the Dumping Yards (DY) ranges from $24 \mathrm{~km}$ to $32 \mathrm{~km}$. However, the optimum distance may differ from city to city, depending on the local topology and transport economics. In such systems, the collected solid wastes are delivered at the transfer stations and then high capacity haulers or multiaxle vehicles haul the solid wastes to the dumping yards. 
Optimization for the handling of SWM was first applied in California (Andersen, 1968). As per Abou Najm et al (2002) and Abou Najm and El-Fadel (2004) with increasing complexity in solid wastes management in the cities of the developing world, selection or setting up of an optimum solid waste management system becomes difficult for technical and operation research professionals. This led to the use of various mathematical models and systems analysis techniques to develop integrated solid wastes management systems. These models fall into categories such as linear and non-linear programming, multi-criteria decision analysis using Geographical Information Systems (GIS), and simulation optimization models (Chang and Wang, 1996). The solid wastes management models developed over the last five decades are with different goals and methodologies. Of these, most of researchers focused on the use of linear and non-linear programming models for MSWM. And with increasing pressure on city managements to minimize the cost of MSWM, cost reduction exercises become vary crucial. Barlishen and Baetz (1996) developed an optimization study using mixed integer linear Programming for facility location. Nema and Modak (1998) developed an Integer Linear Programming model to minimize total costs in handling hazardous waste management systems. Bhat (1996)focused on allocation of trucks in the handling of MSW using simulation models. Karagiannidis et al (2003) developed a simulation based GIS for optimally locating Solid waste management facilities. Paily (2006) applied a Linear Programming model to optimally locate transfer stations given various disposal sites. Yeomans (2007), Sarika Rathi (2007), Rodionov and Nakata (2011), Bernd Noche et al. (2010) and Markovic et al. (2010),used Linear programming models for designing an optimal and sustainable Solid Waste Management Systems for various cities such as Ontario (Canada), Mumbai (India), St. Petersburg (Russia), Duisburg (Germany), and City of Nis (Serbia) respectively. A very useful review on the development of various decision support systems for cost reduction in MSWM, using various optimization systems are presented by Ohri and Singh (2010). The review article by Rajendra K. Kaushal et al. (2010) brought out the current challenges in terms of cost reduction needs in India. In the opinion of Chatzouridis and Komilis (2012), however, only limited research work appears to exist, on the methods to optimally locate and allocate transfer stations, when the available data are only on the generation and on the sink nodes.

In the present paper, the authors analyze the status of waste management in the Chennai Metropolitan Area (CMA) and developedtwo methods, one, a linear programming methodology to optimize the cost of managing the Municipal Solid Wastes Management (MSWM) network, and the other ArcGIS application for optimal routing. The purpose of this research is to optimize the cost of handling and transport of solid wastes from the 200 city wards to 12 transfer stations and to the two dumping yards in the CMA. As the city wards and dumping yards are 'fixed', and the available space within the Corporation is limited to the existing transfer stations, there is need to optimize the number of transfer stations and determine their ideal locations.

The discussion in the paper is in four commissioned parts, namely, (a) the study area and the solid wastes, inclusive of solid waste flows and the current network for collection, transport and disposal, (b) the linear programming model for optimizing transfer stations and reducing cost of handling, (c) the optimal locations for transfer stations and discussion on the model results, and (d) recommendations towards an integrated solid wastes management system for the CMA.

\section{Chennai and Solid Wastes}

Chennai earlier called as Madras, established as a Corporation in the year 1688 by the East India Company, is one of the oldest municipal corporations in India. Thepresent research has been conducted in the area governed by the Corporation of Chennai $(\mathrm{CoC})$ or,administratively, called as CMA. Chennai is the fourth largest metropolitan city in India. It is the capital of the State of Tamil Nadu and is located on the eastern coast $\left(12^{\circ} 85^{\prime} \mathrm{N} 80^{\circ} 13^{\prime} \mathrm{E}\right.$ and $\left.13^{\circ} 23^{\prime} \mathrm{N} 80^{\circ} 34^{\prime} \mathrm{E}\right)$, and covers an area of $426 \mathrm{~km}^{2}$ with a current population of 7.1 million (Census 2011). As per the Annual Report of the CoC, CMA has about 1.4 million households and about 1,136 notified slums. Chennai is divided into 15 administrative zones and 200 city wards(Figure 1).Tables 1 provide the names of the various zones and the wards attached to each zone.The map giving details of Zones, Transfer stations, Dumping yards, Ward- Centroids of CMA are given in Figure 2 and the list of zones along with the wards attached to each zone is given in Table 1. 


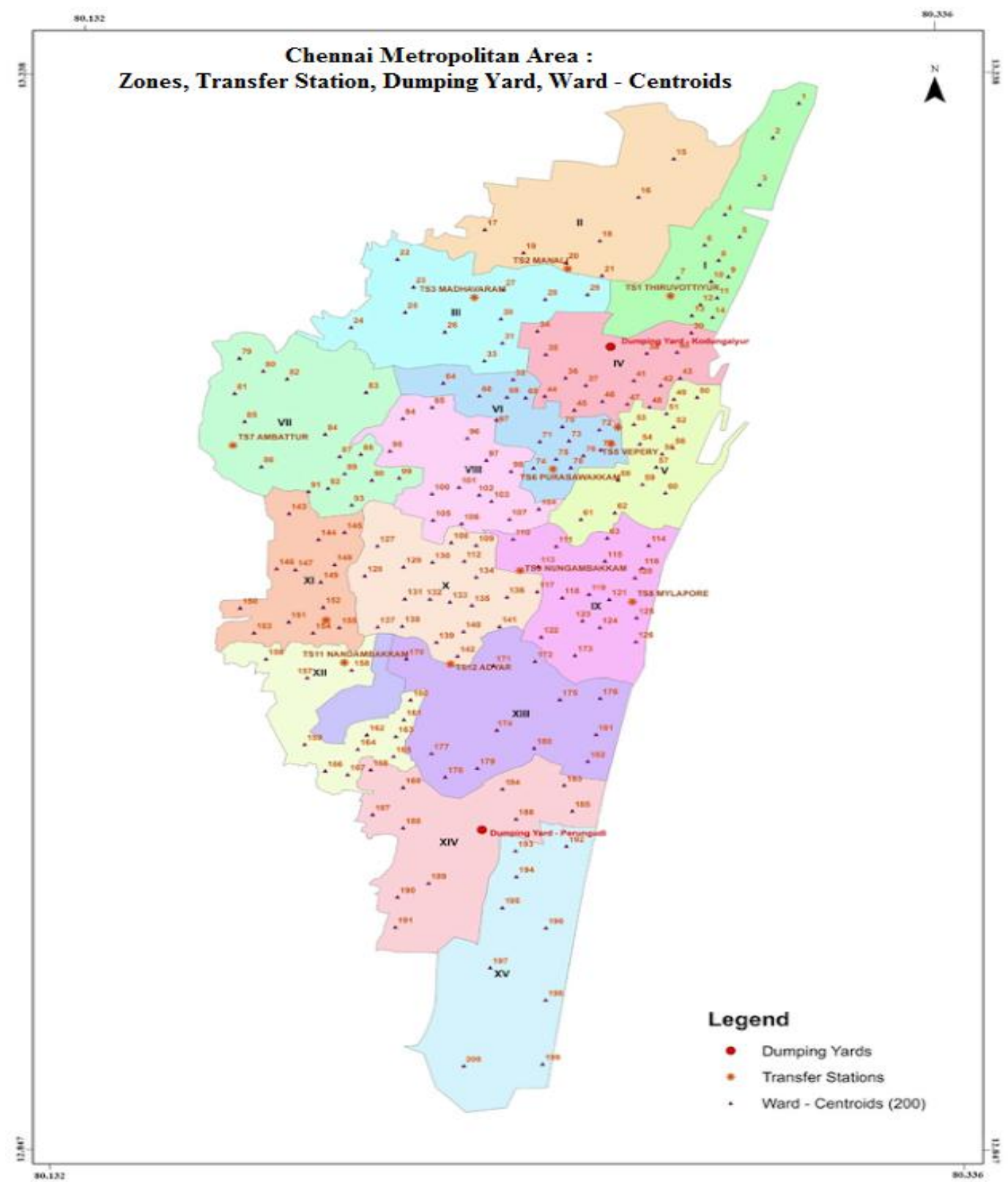

Figure 1 Chennai Metropolitan Area

Zones, Transfer stations, Dumping yards, Ward- Centroids

Table 1 name of the zones with attached ward numbers

\begin{tabular}{|l|l|l|l|}
\hline Serial No. & Zone & Name of the Zone & Ward Numbers \\
\hline 1 & I & Thiruvottiyur & 1 to 14 \\
\hline 2 & II & Manali & 15 to 21 \\
\hline 3 & III & Madhavaram & 22 to 33 \\
\hline 4 & IV & Tondaiarpet & 34 to 48 \\
\hline 5 & V & Royapuram & 49 to 63 \\
\hline 6 & VI & Thiru-Vi-Ka Nagar & 64 to 78 \\
\hline 7 & VII & Ambattur & 79 to 93 \\
\hline 8 & VIII & Anna Nagar & 94 to 108 \\
\hline 9 & IX & Teynampet & 109 to 126 \\
\hline 10 & X & Kodambakkam & 127 to 142 \\
\hline 11 & XI & Valasaravakkam & 143 to 153 \\
\hline 12 & XII & Alandur & 154 to 167 \\
\hline 13 & XIII & Adyar & 170 to 182 \\
\hline 14 & XIV & Perungudi & 168,169, and 183 to 191 \\
\hline 15 & XV & Sholinganallur & 192 to 200 \\
\hline
\end{tabular}


Solid waste management is the one of the major activities of the CoC. This process is however very tedious as it involves collection of garbage generated at every house through various means and then moving the wastes to the two disposal sites or the dumping yards, geographically located at the northern most and southern most points of the CMA.All of the 200 city wards are estimated to generate about 4,840 tons of garbage a day.The cost of handling garbage is increasing year after year, while the budgetary allocations were kept the same. This put pressure on the city engineers to optimize the cost of handling and transporting the solid waste. The composition of solid wastes generated is given in Table 2. Note that the inert and the organic together comprise 67 per cent of all the wastes.

Table 2: Composition of Solid Wastes in Metropolitan Chennai

\begin{tabular}{|l|l|}
\hline Type of Wastes & Percent \\
\hline Inerts & 34.90 \\
\hline Organic & 32.57 \\
\hline Food & 8.10 \\
\hline Wood/timber & 7.00 \\
\hline Paper & 6.50 \\
\hline Consumable plastic & 5.10 \\
\hline Rags and textile & 3.10 \\
\hline Rubber/leather & 1.50 \\
\hline Industrial plastic & 1.20 \\
\hline Others & 0.03 \\
\hline
\end{tabular}

Source: Corporation of Chennai 2013.

The high moisture content in the solid wastes of 27.6 percent compared to the global average of about 10 percent leads to complicated handling of garbage in Chennai.

\subsection{The Solid Waste Flow and Current Network}

Over 19,390 workers are engaged in the sweeping, collection of wastes, managing and operating the transport operations in the MSWM of the CMA. The Corporation employees are engaged in sweeping the streets of the areaat least once a day, using brooms, brushes, wheel bins, wheelbarrows and also long brooms. The collected wastes are dropped into the waste bins along the streets, placed at regular intervals and according to the needs of the city households.

The solid wastes are collected by workers in each of the 200 wards and then transported to transfer stations (the storage points for garbage) and then to the dumping yards. The wastes from the wards closer to the dumping yards are moved directly to the dumping yards. The architecture of current flow of solid wastes from households and streets are shown pictorially in Figure 2.

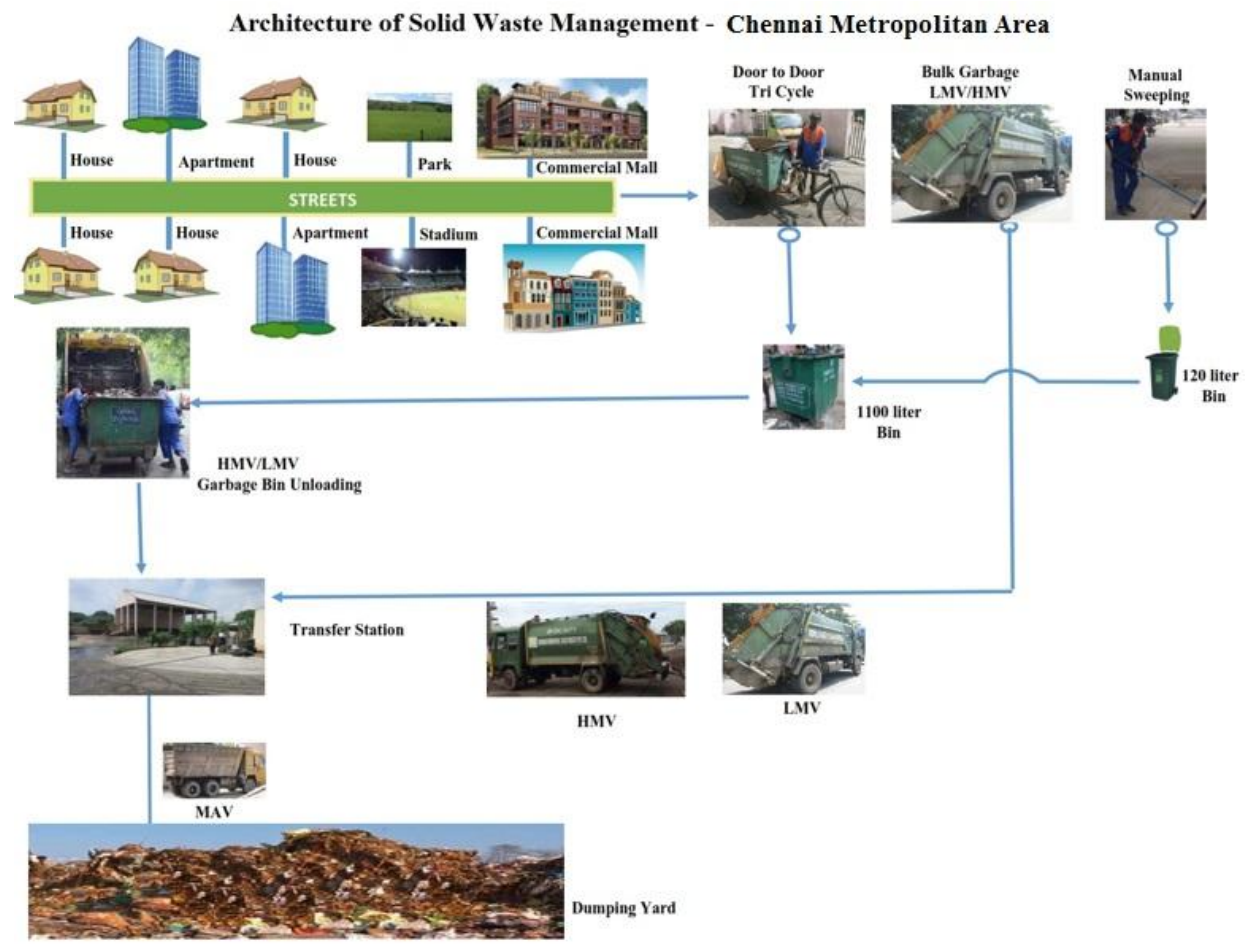


Legend:

LMV - Light Motor Vehicles

HMV- Heavy Motor Vehicles

MAV - Multi Axle Vehicles

Figure 2Architecture of Solid waste management -CMAThe diagram is self-explanatory. The architecture of MSWM show clearly the four components of the SWM system, namely, generation, collection, transport and disposal. While the generation is at the residences, commercial establishments and streets, the collection is also from the same locations; the transport of the municipal wastes is first to the garbage bins using tricycles and wheel barrows, to transfer stations using bulk-garbage open tippers (light and heavy motor vehicles) and then from there to dumping sites using multi-axle vehicles, both light and heavy. The disposal is by open dumping, although some part of the collection is composted at select points in CMA. The current network design is given below in Figure 3.

\section{Current Network Design - Chennai Metropolitan Area}

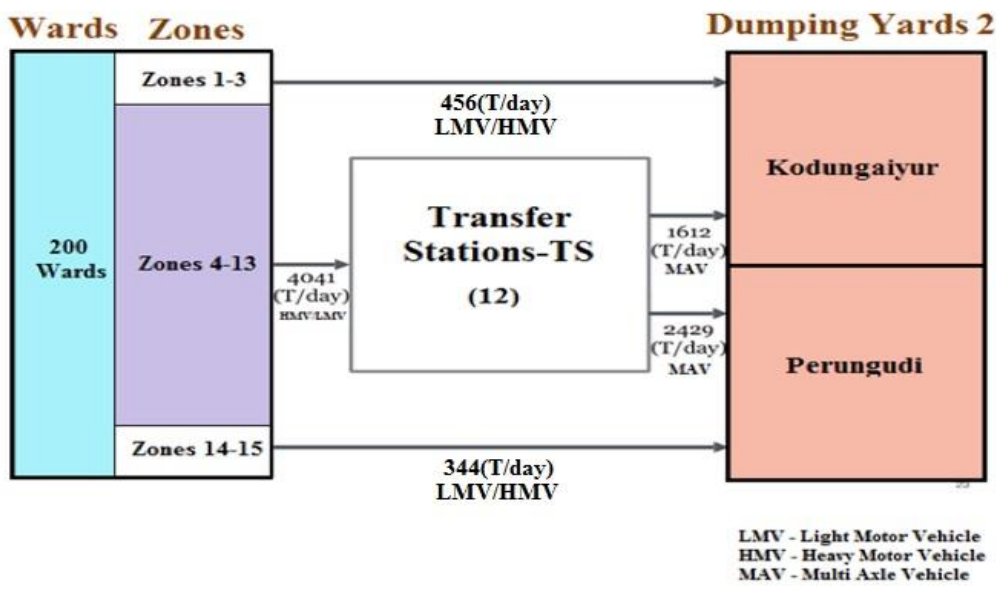

Figure 3

\section{Current network design -CMA}

The network design outlines the fact as to how the wastes from the 200 wards of Corporation in the 15 administrative zones are collected and transported, on a daily tonnage basis, to the 12 transfer stations and then disposed of at the two dumping sites with different types of vehicles. Note the solid wastes from zones 1-3 (456 tons / day) and zones 14-15 (344 tons / day) are directly dumped at the dumping yards at Kodungaiyur and Perungudi, respectively. A total of 4,041 tons / day is transferred to 12 transfer stations from zones 4-13 and then disposed of at 1,612 tons / day at Kodungaiyur dumping site and at 2,429 tons / day at Perungudi dumping site. Thus, a total of 4,841 tons of solid wastes are collected, transported and disposed of in the metropolitan city of Chennai every day. Low capacity vehicles are used to haul the garbage collected from the households and street bins.

\section{Need and objective for the study}

Presently, there are 12transfer stations in use in CMA and theywere created over the last 30 years, without any optimization study. The elected representativesof wards generally apply pressure on the city management for cleaning up the garbage in a speedy way and to carry out the same, new transfer stations were opened up, without any optimization study. There were added reasons such as: one, to store and ensure movement through large capacity vehicles to reduce the cost of transportation and to store the fluctuating, dayto-day generation of the wastes in the city.The solid wastes collected from the 200 wards are transferred through the 12 transfer stations to the two dumping yards. With multiple transfer stations, which were created over a period of time in the CMA, there was a felt need to identify the most optimal operation, to minimize the cost of handling garbage.As no optimization study was done in the past, City managers and Engineers requested for a study to identify the optimal number of Transfer stations, given the current annual garbage generation at various wards and the existing dumping yards.

The objective for the study is defined as

- To optimize the cost of handling solid wastes from the generation points (households and institutions) to transfer stations and the dumping yards in CMA using a model of Linear Programming for optimization. 


\section{Data, Model and Methods}

The data required for the project were collected from the available real data in the web site of $\mathrm{CoC}$. The datasets collected for the research reported hereinclude the following:

- Gravity locations (centroids) for generation of solid wastes for each of the 200 wards.

- Daily generation of solid wastes by wards (there are no appreciable seasonal changes in the generation and collection of solid waste in Chennai city)

- Locations of current transfer stations (12) and current wards covered by each of the transfer stations.

- Locations of dumpingyards (DY) and transfer stations covered by each of the dumping yards.

- Cost of managing each of the transfer stations.

- Current costs of running light motor vehicles (LMV), heavy motor vehicles (HMV) and multi-axle vehicles(MAV).

- LMV, HMV and MAV in operation

- Distance calculations based on latitude and longitude information.

The latitude-longitude distances are converted into actual distances $(\mathrm{km})$,by verifying and comparing sample calculations between Google map distances and latitude-longitude based distances.It was found that the map distance is 1.62 times of the latitude-longitude distances on the average. Hence this factor 1.62 is used to convert the latitude-longitude distance into actual distance. The maps showing ward boundaries and centroids with $\mathrm{x}, \mathrm{y}$ coordinates (latitudes and longitudes) are shown in Figure 6. The maps have been essential in the computation of distances between ward-centroids and transfer stations and transfer stations and dumping yards. Solid wastes from transfer stations 1 to 6 are disposed of at Kodungaiyur and the wastes from the remaining transfer stations 7 to 12 are moved to Perungudi.

\subsection{Linear Programming Model}

The key elements of optimization model adopted for study is as shown in the following paragraphs.

\subsubsection{Model Assumptions}

The model assumptions are:

- Each ward has a single loading point.(Centroid, details given in Table 3)

- Distance between ward and transfer station / dumping yard and between transfer stations and dumping yards are taken to be 162 per cent of the latitude-longitude distance.(Details of the coordinates of Transfer Stations and Dumping Yards are given in Table 4)

- The loaded vehicles move from transfer stations to dumping yards and return empty. As the vehicles return empty to the starting points, after consulting the $\mathrm{CoC}$ engineers, it has been estimated that one trip equals 1.8 times the distance between two points, say between ward and transfer station and from transfer station and dumping yard. Similar is the case with LMVs and HMVs.

- Each transfer station owns a fleet of LMVs and HMVs.

- Each dumping yard owns a fleet of MAVs.

- Solid wastes from a ward can be transferred only to a single transfer station or to a single dumping yard.

- Routes considered in the study are the haul routesthat connect wards to transfer station / dumping yard directly and transfer station to dumping yard directly.

- Wards are not connected to each other. Transfer stations are not connected to each other, and dumping yards are not connected to each other.

- Only 12 transfer stations and 2 dumping yards are the available entities. Distances are calculated from each of the 200 wards to these 14 entities.

\subsubsection{Basic Constraints}

The basic constraints of the model in the study are:

- Each of the dumping yards can receive a maximum of 1000 tonsa day from the wards. This is due to constraints in compactor unloading delays at dumping yards and loading delays at wards in regard to multiaxle vehicles.

- A given ward can dispatch garbage only to one receiving point, that is, it could be either a dumping yard or a transfer station.

- The maximum a transfer station can handle is about 600 tonsof solid wastes a day and the capacity of the transfer station could be either 300 or 600 tons. 
The trucking and other costs incurred in the collection and transport of solid wastes in the CMA are in respect of:

- Solid waste flow from the city wards to transfer stations, transported by the compactors in HMVs and LMVs and the solid waste flow from transfer stations to dumping yards, transported using the MAVs.

- Wherever the solid waste is transported directly to dumping yards form the wards only HMVs and LMVs are used.

Table 3 Chennai Metro Area: Ward-Centroids(Latitudes and Longitudes - x, ycoordinates)

\begin{tabular}{|c|c|c|c|c|c|c|c|c|c|c|c|}
\hline Ward No & Latitude & Longitude & Ward No & Latitude & Longitude & Ward No & Latitude & Longitude & Ward No & Latitude & ingitude \\
\hline 1 & 13.2275 & 80.3273 & 51 & 13.1113 & 80.2858 & 101 & 13.0837 & 80.2209 & 151 & 13.0333 & 80.1676 \\
\hline 2 & 13.2146 & 80.3192 & 52 & 13.1063 & 80.2881 & 102 & 13.0808 & 80.2273 & 152 & 13.0388 & 80.1784 \\
\hline 3 & 13.1969 & 80.3150 & 53 & 13.1072 & 80.2756 & 103 & 13.0785 & 80.2311 & 153 & 13.0292 & 80.1568 \\
\hline 4 & 13.1858 & 80.3041 & 54 & 13.1000 & 80.2775 & 104 & 13.0756 & 80.2459 & 154 & 13.0292 & 80.1753 \\
\hline 5 & 13.1775 & 80.3088 & 55 & 13.0962 & 80.2844 & 105 & 13.0714 & 80.2128 & 155 & 13.0312 & 80.1835 \\
\hline 6 & 13.1744 & 80.2978 & 56 & 13.0985 & 80.2878 & 106 & 13.0701 & 80.2217 & 156 & 13.0194 & 80.1605 \\
\hline 7 & 13.1621 & 80.2894 & 57 & 13.0912 & 80.2826 & 107 & 13.0717 & 80.2367 & 157 & 13.0124 & 80.1734 \\
\hline 8 & 13.1687 & 80.3022 & 58 & 13.0864 & 80.2707 & 108 & 13.0630 & 80.2184 & 158 & 13.0153 & 80.1873 \\
\hline 9 & 13.1626 & 80.3052 & 59 & 13.0848 & 80.2784 & 109 & 13.0620 & 80.2263 & 159 & 12.9909 & 80.1717 \\
\hline 10 & 13.1607 & 80.2998 & 60 & 13.0815 & 80.2855 & 110 & 13.0643 & 80.2379 & 160 & 13.0041 & 80.2058 \\
\hline 11 & 13.1546 & 80.3017 & 61 & 13.0717 & 80.2590 & 111 & 3.0616 & 80.2514 & 161 & 12.9967 & 80.2037 \\
\hline 12 & 13.1521 & 80.2965 & 62 & 13.0742 & 80.2697 & 112 & 13.0560 & 80.2225 & 162 & 12.9911 & 80.1921 \\
\hline 13 & 13.1480 & 80.2938 & 63 & 13.0647 & 80.2673 & 113 & 13.0540 & 80.2456 & 163 & 12.9904 & 80.2012 \\
\hline 14 & 13.1474 & 80.3003 & 64 & 13.1227 & 80.2160 & 114 & 3.0619 & 0.2803 & 164 & 12.9857 & 80.1893 \\
\hline 15 & 13.2066 & 80.2882 & 65 & 13.1136 & 80.2125 & 115 & 13.0560 & 80.2666 & 165 & 12.9830 & 80.2005 \\
\hline 16 & 13.1923 & 80.2771 & 66 & 13.1179 & 80.2273 & 116 & 13.0534 & 80.2782 & 166 & 12.9775 & 80.1790 \\
\hline 17 & 13.1801 & 80.2290 & 67 & 13.1089 & 26 & & & 80.2454 & . & 12.9762 & 80.1861 \\
\hline 18 & 13.1760 & 80.2650 & 68 & 13.1174 & 80.2359 & 118 & 3.0423 & 80.2533 & 168 & 12.9779 & 80.1933 \\
\hline 19 & 13.1715 & 80.2411 & 69 & 13.1172 & 80.2418 & 119 & 13.0436 & 80.2616 & 169 & 12.9713 & 80.2034 \\
\hline 20 & 13 & 80.2545 & 70 & & & & & & & 13.0195 & 80.2045 \\
\hline 21 & 13.1629 & 80.2657 & 71 & 13.1008 & 80.2462 & 121 & 3.0417 & 80.2680 & 171 & 13.0170 & 80.2317 \\
\hline 22 & 13.1690 & 80.2017 & 72 & 13.1053 & 80.2648 & 122 & 13.0277 & 0.2466 & 172 & 13.0185 & 80.2447 \\
\hline 23 & & 57 & 73 & & & 12 & & 0.2595 & 173 & 13.0207 & 80.2572 \\
\hline 24 & 13.1435 & 80.1872 & 74 & 13.0909 & .2442 & 124 & 3.0312 & 80.2650 & 174 & 12.9928 & 80.2327 \\
\hline 25 & 13.1492 & 80.2041 & 75 & 13.0942 & 80.2513 & 125 & 13.0348 & 80.2765 & 175 & 13.0042 & 80.2525 \\
\hline 26 & 13.1419 & 80.2165 & 76 & & & 126 & 13.0259 & 80.2763 & 176 & 13.0046 & 80.2651 \\
\hline 27 & 13.1576 & & 77 & 77 & & & & & & 12.9840 & 80.2123 \\
\hline 28 & 13.1540 & 80.2479 & 78 & 13.0910 & 80.2559 & 128 & 3.0505 & 0.1914 & 178 & 12.9753 & 80.2166 \\
\hline 29 & 13.1559 & 80.2611 & 79 & 13.1320 & 80.1522 & 125 & 3.0539 & 0.2036 & 179 & 12.9785 & 80.2266 \\
\hline 30 & 13 & & 80 & & & & & & & & 80.2444 \\
\hline 31 & 13.1377 & 80.2345 & 81 & 13.1188 & 80.1507 & 131 & 3.0419 & 0.2040 & 181 & 12.9912 & 80.2638 \\
\hline 32 & 13.1240 & 80.2379 & 82 & 13.1243 & 80.1671 & 132 & 13.0418 & 0.2119 & 182 & 12.9811 & 80.2612 \\
\hline 33 & 13 & 80 & 83 & & & 13 & & & 183 & 12.9721 & 80.2539 \\
\hline 34 & 13.1422 & 80.2454 & 84 & 35 & 90 & 13 & 3.0501 & 0.2263 & 184 & 12.9708 & 80.2345 \\
\hline 35 & 13 & 8 & 85 & 13 & & 13 & 13.0395 & 0.2250 & 185 & 12.9625 & 80.2564 \\
\hline 36 & 13.1246 & $8 c$ & 86 & 13 & 91 & 13 & 26 & 0.2359 & 186 & 12.9595 & 80.2389 \\
\hline 37 & 13.1219 & & 87 & & & 13 & & 954 & 18 & .9612 & 80.1939 \\
\hline 38 & 13 & 8 & 88 & & & 13 & & & 188 & 12.9562 & 80.2034 \\
\hline 39 & 13.1416 & 80.2937 & 89 & 13.0888 & 80.1851 & 13 & 3.0257 & 0.2139 & 189 & 12.9355 & 80.2114 \\
\hline 40 & & & 90 & & & & & & & & 80.2017 \\
\hline 41 & 13 & & 91 & & & 14 & 16 & & 191 & 191 & 80.2010 \\
\hline 42 & 13.1219 & 80.2840 & 92 & 13.0833 & 8 & 14 & 13.0205 & 80.2204 & 192 & 12.9494 & 80.2545 \\
\hline 4 & 13.1246 & 8 & 93 & & & 14 & & 0.1677 & 15 & 12.9476 & 80.2387 \\
\hline 4 & & & 94 & & & & & & & & \\
\hline 45 & 13.1126 & 80.2570 & 95 & 13.0972 & 80.1993 & 145 & 13.0668 & 80.1851 & 195 & 12.9264 & 80.2345 \\
\hline 46 & 13.1159 & & 96 & & & 14 & & & 196 & & \\
\hline 47 & & & & & & & & & & & \\
\hline 48 & $\begin{array}{l}13.1137 \\
\end{array}$ & 80.2806 & 98 & 13.0897 & & 14 & & 320 & 198 & & \\
\hline 49 & 13.1167 & 80.2882 & 99 & 13.0872 & .2022 & 14 & 13.0482 & 80.1777 & 199 & 12.8678 & 80.2471 \\
\hline 5 & 13.1174 & 80.2955 & 100 & 3.0812 & .2125 & 150 & 13.0385 & 80.1524 & 200 & 12.8671 & \\
\hline
\end{tabular}

Table 4: Chennai Metro Area: Transfer Stations and Dumping Yards with coordinates

\begin{tabular}{|c|c|c|c|c|c|c|}
\hline No.of TS & Zone & $\begin{array}{l}\text { Zone } \\
\text { number }\end{array}$ & $\begin{array}{l}\text { Wards } \\
\text { Covered }\end{array}$ & Address & Latitude & Longitude \\
\hline TS1 & Collection Point & 1 & 1 to 14 & Manali High Road, Sathangadu & 13.155 & 80.287 \\
\hline TS2 & Collection Point & 2 & 15 to 22 & KamarajSalai, Manali & 13.165 & 80.254 \\
\hline TS3 & Collection Point & 3 & 23 to 33 & Omakkulam, Kilburn Nagar & 13.154 & 80.225 \\
\hline TS4 & Modern Transfer Station & 4 & 34 to 48 & Basin Bridge Road & 13.106 & 80.270 \\
\hline TS5 & Modern Transfer Station & 5 and 8 & $\begin{array}{l}49 \text { to } 63 \text { and } \\
94 \text { to } 108\end{array}$ & $\begin{array}{l}\text { Basin Elephant Gate Bridge } \\
\text { Road }\end{array}$ & 13.094 & 80.268 \\
\hline TS6 & Modern Transfer Station & 6 & 64 to 78 & $\begin{array}{l}1^{\text {st }} \text { Main Road, S.S. Puram, 'A' } \\
\text { Block }\end{array}$ & 13.090 & 80.250 \\
\hline TS7 & Modern Transfer Station & 7 & 79 to 93 & Vanakaram Road, Athipattu & 13.099 & 80.150 \\
\hline TS8 & Modern Transfer Station & 9 & 109 to 196 & Karaneeswara Pakoda St., & 13.040 & 80.275 \\
\hline TS9 & Modern Transfer Station & 10 & 127 to 142 & 12, Kodambakkam High Road & 13.052 & 80.240 \\
\hline TS10 & Modern Transfer Station & 11 & 143 to 155 & Bharathi Salai & 13.033 & 80.179 \\
\hline TS11 & Modern Transfer Station & 12 & 156 to 167 & $\begin{array}{l}\text { Nandambakkam Service Road, } \\
\text { M.G.R. Nagar }\end{array}$ & 13.017 & 80.185 \\
\hline TS12 & Modern Transfer Station & 13 & 170 to 182 & $\begin{array}{l}\text { Alandur Salai, } \quad \text { Saidapet, } \\
\text { Chennai } 600015\end{array}$ & 13.017 & 80.218 \\
\hline $\begin{array}{l}\text { Direct } \\
\text { dumping }\end{array}$ & Zones 14 and 15. & 14 and 15 & $\begin{array}{l}183 \text { to } 200 \\
\text { and } 168,169\end{array}$ & $\begin{array}{l}\text { Directly dumped at Perungudi } \\
\text { dumping yard }\end{array}$ & 12.955 & 80.228 \\
\hline \multicolumn{4}{|c|}{ Dumping yard } & Kodungaiyur & 13.136 & 80.268 \\
\hline \multicolumn{4}{|c|}{ Dumping yard } & Perungudi & 12.955 & 80.228 \\
\hline
\end{tabular}

Source: Corporation of Chennai and Google Map 
The HMV, LMV and MAV details and the costs incurred to the CMAare given in Tables 5below.

Table 5: Haul transport (HMV, LMY, MAV), loads, trips and costs

\begin{tabular}{|l|l|l|l|}
\hline Parameters & Compactor HMV- $\boldsymbol{H} \boldsymbol{M} \boldsymbol{V}$ & Compactor LMV- CLMV & MAVs -CMAV \\
\hline Total numbers & 190 & 126 & 84 \\
\hline Loadability (tons) & 9 & 5 & 14 \\
\hline Trips per day (NOs) & 2 & 3 & 3 \\
\hline Transport cost (INR) & 66 & 40 & 82 \\
\hline Monthly Cost to The Company (CTC) & 12500 & 8333 & 9000 \\
for driver per trip in INR & SHMV & SLMV & SMA \\
\hline
\end{tabular}

Source: Corporation of Chennai 2013.(INR- Indian Rupees, the local currency)

The details of staff at eachtransfer stationand the total cost per month in INR to the CoCare given table 6.

Table 6: Staffs and costs of each transfer station

\begin{tabular}{|l|l|l|}
\hline Post -Staff (Cost To Company per month per post in INR) & Number & Total Cost / month inINR \\
\hline Superintendent (26000) & 1 & 26000 \\
\hline Data entry operator (15000) & 2 & 30000 \\
\hline Sweeper (9000) & 3 & 27000 \\
\hline
\end{tabular}

Source: Corporation of Chennai 2013

Note: Each transfer station has the following staffsand the total cost per month in INR to the CoC, for each position is given in brackets.

The transfer station costs per month work out to: Salaries and others:INR 83,000; Space cost: INR 117,000; and Total Cost(Fixed Costs):INR 200,000. In addition to the fixed costs, one JCB dumper operates on variable cost basis for lifting the garbage and loading the same on to the MAVs. As per available data, JCB dumpers handle only 25 percent $(\mathrm{Q})$ of the garbage. The balance is unloaded directly from HMVs/LMVs to MAVs through gravity method. The hiring costs for a JCB (variable) isINR $24(\mathrm{R})$ per ton of solid wastes handled.The current cost component that is optimizedis INR 367.2 per ton.

\subsubsection{Variables}

Counter: $i$ - two hundred wards; $j$ - twelve transfer stations and two dumping yards;m - twelve transfer stations, $l$ - two dump yards; $D P i j$ - distance between ward $i$ and transfer stations/dumping yards $j$; DSml- distance between transfer stations and dumping yards

$i$ - source - wards (200)

$j-$ transfer stations and dumping yards (14)

$m$ - transfer stations (12)

$l$-dump yards (2)

$D P i j$ - distance between ward i and transfer station or dump yard $j$

$D S m l$ - distance between transfer stations $m$ and dumping yards $l$

$\boldsymbol{w i}$-solid waste quantity (weight) from wards $i$

$N L M V$ - number of available Light Motor Vehicles

$N H M V$ - number of available Heavy Motor Vehicles

$N M A V$ - number of available Multi Axle Vehicles

\subsubsection{Decision variables}

Cij-Connectivity between wards $i$ and transfer stations/dumping yards $j$ (type: binary);

$\mathrm{Hij}$ - number of trips of HMV vehicles between ward iand transfer stations/dumping yards $j$ (type: non-negative integer);

Lij- number of trips of LMV vehicles between wardsi and transfer stations/dumping yards $j$ (type: non-negative integer);

$M m l$ - number of trips of MAV vehicles between transfer stations $m$ and dumping yardsl (type: non-negative integer); and

$K m$ - type of transfer stations $m$ (type: non-negative integer; upper limit: 2).

\subsubsection{Objective of the model}

The objective is to minimize the total transport cost in the network from generating nodes to sink nodes, fixed cost of managing a TS and handling cost at TS. The cost elements taken for this study are the transport cost for all the three types of vehicles, and separately the cost of Drivers and Helpers for the vehicles, the space cost at TSs, the administrative cost of TSs. 


$$
\min _{C_{i j}, H_{i j}, L_{i j}, M_{m l}, K_{m}} \text { HMVtripcost }+ \text { LMVtripcost }+ \text { MAVtripcost }+ \text { TSfixedcost }+ \text { Forkliftcost }
$$

where,

$$
\begin{aligned}
& \text { HMVtripcost }=\sum_{i=1}^{200} \sum_{j=1}^{14} H_{i j}\left(D P_{i j} \times t \times C_{H M V} \times 30+S_{H M V}\right) \\
& \text { LMVtripcost }=\sum_{i=1}^{200} \sum_{j=1}^{14} L_{i j}\left(D P_{i j} \times t \times C_{L M V} \times 30+S_{L M V}\right) \\
& \text { MAVtripcost }=\sum_{i=1}^{12} \sum_{j=1}^{2} M_{m l}\left(D S_{m l} \times t \times C_{M A V} \times 30+S_{M A V}\right) \\
& \text { TSfixedcost }=\sum_{m=1}^{12} K_{m} \times F C \\
& \text { Forkliftcost }=\sum_{i=1}^{200} \sum_{m=1}^{14} C_{i m} \times w_{i} \times Q \times R \times 30(1)
\end{aligned}
$$

\subsubsection{Constraints}

Following constraints restricts the number of connections for any ward to be one.

$\sum_{j=1}^{14} C_{i j}=1 \quad \forall_{i, j}(2)$

Above constraints and variable $C i j$ are not required if there is no upper limit on capacity of transfer stations (variables $H i j$ and $L i j$ are sufficient to denote connections). With the upper limit in place, load from a ward might be split and sent to two or more transfer stations. Further, for trips and connections between wards and transfer stations to be consistent following constraints are added.

$L_{H M V} \times H_{i j}+L_{L M V} \times L_{i j} \geq C_{i j} \times w_{i} \forall_{i, j}$

To minimize the trip cost, solver decreases $H i j$ and $L i j$. If a connection between ward $i$ and transfer station/dump yard $j$ exists (i.e. Cij equals one) number of $H i j$ and $L i j$ cannot be lesser than required to transfer load from ward $i$. At optimum, when a particular $C i j=0, H i j$ and $L i j$ will be zero as unnecessary presence of trip results in excess cost. Intuitively, a connection and corresponding trips between $i$ and $j$ either coexist or become zero together at optimum. To restrict the feasible solution space, following constraints are added,

$L_{-} H M V \times H_{-} i j+L_{-} L M V \times L_{-} i j \leq C_{-} i j \times w_{-} i+L_{-} L M V \forall_{-}(i, j)$

Both number of HMV and LMV can be included as vector variables (single variable per ward) instead of matrices. However, cost function will become quadratic as $\mathrm{Cij}$ needs to be multiplied with number of HMV's and LMV's to estimate optimal trip distance.

Type of transfer stations $(0,1,2)$ and capacity of transfer stations $(600$ ton as maximum) are limited by following constraint

$$
\begin{aligned}
& K_{-} m \leq 2 \quad \forall \_m \\
& 300 \times K_{m} \leq \sum_{i=1}^{200} C_{i m} \times w_{i} \forall_{m}(6)
\end{aligned}
$$

Above constraint is applied for each of the twelve transfer stations (i.e. for all $\mathrm{k}$ ). It identifies whether the transfer station is present $(\mathrm{Km}>0)$ or not $(\mathrm{Km}=0)$ and if present whether it is of $300(\mathrm{Km}=1)$ or $600(\mathrm{Km}$ $=2$ ) ton capacity.

In the case of load transfer from Transfer station to dump yard, no connectivity variable is used, as there is no upper limit on capacities of dump yards is enforced. To estimate number of multi axial vehicles and limit the feasible solution space following constraints are enforced,

$$
\begin{gathered}
L_{M A V} \times M_{m l} \leq \sum_{i=1}^{200} C_{i m} \times w_{i} \forall_{m, l}(7) \\
L_{M A V} \times M_{m l} \geq \sum_{i=1}^{200} C_{i m} \times w_{i}+L_{M A V} \forall_{m, l}
\end{gathered}
$$


Further, number of vehicles available for transport should more than or equal to the required number of trips. Assuming 3 trips per LMV, 2 trips per HMV and 4 trips per MAV. Following constraints are applied.

$$
\begin{aligned}
& \sum_{i=1}^{200} \sum_{i=1}^{14} H_{i j} \leq 2 \times N_{H M V} \\
& \sum_{i=1}^{200} \sum_{i=1}^{14} L_{i j} \leq 3 \times N_{L M V} \\
& \sum_{m=1}^{12} \sum_{l=1}^{2} M_{m l} \leq 4 \times N_{M A V}
\end{aligned}
$$

The above LP was run using LINDO (Linear,Interactive, and Discrete Optimizer). All the data needed for running the model were prepared in the required format. All data were also validated with the engineers of CMA.

\section{Results}

The LINDO model was run with the actual field data ofCMA in terms of 200 wards, solid wastes handled by each ward, totaling to 4,840 tons a day, 12 transfer stations, 2 dumping yards, and the details on transport vehicles (HMV, LMV, MAV) availability. For the given objective function of optimum transfer cost and the constraints given above, the Linear Programming model was run with the following logic.

As a first step, each ward identifies the nearest located entity of dumping yard or transfer station. Variable Cij indicates the Connectivity between wards and transfer station/ dumping yard. If it is DY after verifying the available capacity (permitted capacity minus allocated tonnage to the DY) and checking the sum of the tonnage of the new ward under consideration and the already allocated tonnage do not exceed the permitted capacity, allow the ward to send the solid waste to the DY.

But if it is nearer a transfer station then the tonnage that is checked is the permitted capacity of TS. This process is repeated until all the solid waste from all the wards are allocated either to DY or TS. For any individual TS or DY, Cij values indicate the wards connected to it. Optimum allocation of tonnages for each TS or DY is computed by adding Tonnages generated in the wards connected to respective TS/DY. Capacity of the transfer station is optimally chosen by the LP model either 300 or 600 tons and indicated by the variable K_m.

Presence of TS and DY are denoted by binary variables in the problem formulation. That is 1 if a TS/DY is present and 0 if a TS/DY is not present. The Lindo Solver has chosen in addition to two Dys, only eight transfer stations to be the optimal number transfer stations, required for the process. Further, sensitivity analysis also shows that increase in number of transfer station leads to increase in operating cost. Tonnages to be handled by the optimal (suggested) transfer stations, which are by the designations from the existing transfer stations are given in Table 7.

Table 7 Suggested Transfer stations and respective volumes

\begin{tabular}{|l|l|l|l|}
\hline $\begin{array}{l}\text { Transfer } \\
\text { Station } \\
\text { number }\end{array}$ & Transfer Station code & $\begin{array}{l}\text { Recommended } \\
\text { (Tons /day) }\end{array}$ & $\begin{array}{l}\text { Maximum } \\
\text { tonnage permitted }\end{array}$ \\
\hline $\mathbf{1}$ & TS1 & 277.4 & 600 \\
\hline $\mathbf{2}$ & TS3 & 311.6 & 600 \\
\hline $\mathbf{3}$ & TS4 & 281.1 & 600 \\
\hline $\mathbf{4}$ & TS5 & 293.8 & 600 \\
\hline $\mathbf{5}$ & TS6 & 598.7 & 600 \\
\hline $\mathbf{6}$ & TS10 & 279.2 & 600 \\
\hline $\mathbf{7}$ & TS1 & 294.5 & 600 \\
\hline $\mathbf{8}$ & TS12 & 511.2 & 600 \\
\hline & Direct to DY1 & 999.5 & 1000 \\
\hline & Direct to DY2 & 993.0 & 1000 \\
\hline & Total & 4840.0 & \\
\hline
\end{tabular}

Thus the optimum number of Transfer Stations comes to eight.

At optimum level, the cost (INR per Tonne) is 245.60 compared to the current cost of INR 367.20 per tonne .Thus there is considerable savings of INR 121.60 per tonne ( 33.1 percent of current cost levels )

Chatzouridis and Komilis,(2012) have carried out Similar study for a region consisting of 53 Municipalities in Greece by using Linear Programming and the optimal solution suggested that from 47 candidate TSs , 12 transfer stations will meet the needs. In this study, the authors have taken a large city with fixed locations of TSs and then optimized the low cost locations in terms of how many TSs are needed and what are the tonnages that will be handled by each TS and Dumping yard. Here the authors have analyzed a live issue. The choice of relocating the TSs is not feasible as with in the limits of CMA, there is no space to accommodate TS and even if it is available the fixed cost of acquiring the space is abnormally high. 


\subsection{Scenario Analysis}

In order to test the various scenarios of the model, the optimization model was run without any TS, meaning all the 200 wards would transfer directly to the DYs. The theoretical minimum cost came to INR 227.6 per ton. This option is impractical due to number of issues such as high unloading time at DYs, extended collection time for multi axle vehicles, available vehicle capacities, increase in number of vehicles and operating staff etc.

Table 8 Number of transfer stations vs. cost

\begin{tabular}{|l|l|}
\hline $\begin{array}{l}\text { Transfer stations } \\
\text { Numbers) }\end{array}$ & $\begin{array}{l}\text { Total cost } \\
\text { (INR/Ton) }\end{array}$ \\
\hline 5 & 231.1 \\
\hline 6 & 234.7 \\
\hline 8 & 245.6 \\
\hline 9 & 273.4 \\
\hline 10 & 302.8 \\
\hline 11 & 334.5 \\
\hline 12 & 367.2 \\
\hline
\end{tabular}

Source: Linear Programming computations

The model was run repeatedly by increasing the number of TSs from one to 12.The feasible solution was available only when the number of transfer stations reached five. Then,by increasing the number of available transfer stations to $6,7,8,9,10,11$, and 12 , the cost per ton were arrived. The details are given in Table 8.

\section{Conclusion and Recommendations}

Based on this study, it is concluded that CMA has to operate with eight TSs and close the balance four namely TS2, TS7, TS8, and TS9. The implementation of the recommendations will bring in a saving of INR 214.8 Million per year (US\$ 3.52 Million) to CoC.

As CMA has no free space available, the choice of relocating the TSs is not feasible. However the City has developed a master Plan 2026, as per which the area covered by CMAwill be increased to $1189 \mathrm{~km} 2$ from the present 426. Taking into account the increase in population to 12.58 million by the year 2026 and the increase in standard of living of citizens the Solid waste is expected to touch 8950 tons per day.

With the availability of free space in expanded areas of the city, and with availability of technologically superior vehicles to transport the SW, further study need to be carried out to decide on the optimum location and number of TSs desired by 2026. As per USEPA (1977), the threshold one-way distance between a city and the DY area is about 24 to $32 \mathrm{~km}$. This break-even distance need to be studied keeping in mind the increase in fuel price, the available transportation technology, the quantity of available SW, and the sensitivity of local citizens for having DY.

[1]. Abou Najm,M., El-Fadel M., 2004.Computer-based interface for an integrated solid waste management optimization model. Environmental Modeling and Software.19,1151-1164

[2]. Abou Najm, M., El-Fadel, M., Ayoub, G., El-Taha, M., Al-Awar,F., 2002.An optimization model for regional integrated solid waste management 1 Model Formulation. Waste management and Research. 20, 37-45.

[3]. Anderson, 1968. A mathematical model for the optimization of a waste management system. Sanitary Engineering Research Laboratory SERL report. No. 68-1. Berkeley: university of California.

[4]. Barlishen, K.D., and Baetz, B.W., 1996. Development of a decision support system for municipal solid waste management systems planning. Journal of Waste Management \& Research. 14 (1), 71-86.

[5]. Bernd Noche, Trin Chinakupt, Fathi A. Rhoma and Mandar Jawale, 2010. Optimization Model for Solid Waste Management System Network Design Case Study. Second International Conference on solid waste Singapore Computer and Automation Engineering. 5,230-236.

[6]. Bhat, 1996. A Model for optimal allocation of trucks for Solid Waste management. Waste management \& Research. 14,87-96.

[7]. Chang, N., B., Wang S.F., (1996). Solid Waste System analysis by Multi objective Mixed Integer Analysis, Journal of Environmental management.48:17-43.

[8]. Chalmin, P., Gaillochet, C., 2009. Waste to resource, An abstract of World Waste Survey, Cyclope, Veolia. Environmental Services, Edition Economica, France.

[9]. Chatzouridis, C., Komilis, D., 2012. A methodology to optimally site and design municipal solid waste transfer stations using binary programming. Resources, Conservation and Recycling. 60, 89-98.

[10]. Corporation of Chennai. Annual Budget 2014-15, 2014. Government of Tamil Nadu, Chennai, India.

[11]. Essaku S., Swaminathan A., Parthiba Karthikeyan O., Kurian J., Palanivelu K., 2007. Municipal Solid Waste Management in Chennai City, India. Eleventh International Waste Management and landfill symposium, Cagliari, Italy. (1-5 Oct)

[12]. Ghose, M.K., Dikshit, A.K., Sharma, S.K., 2006. A GIS based transportation model for solid waste disposal - A case study on Asansol municipality. Waste Management. 26(11), 1287- 1293.

[13]. Hina Zia, Devadas V., 2008. Urban solid waste management in Kanpur: Opportunities and perspectives, Habitat International. 32,58-73. 
[14]. Karagiannidis, A., Moussiopoulos, N., Diamandopoulos, G., Kaggelides, K., Perkoulidis, G., 2003. Simulation modelling software for integrated solid waste management at regional level. 8th International Conference on Environmental Science \& Technology Lemnos Island, Greece, 8-10 Sep.

[15]. Katkar, A., 2012. Improvement of Solid Waste Collection by using Optimization Technique. International Journal of Multidisciplinary Research. 2 (4).

[16]. Komilis, D., 2008. Conceptual models to optimize the haul and transfer of municipal solid waste. Waste Management and Research. 28, 2355-2365.

[17]. Markovic, D., Janosevic, D., Jovanovic, M., Nikolic, V., 2010. Application method for Optimization in Solid waste management system in the city of NIS. Mechanical Engineering, 8(1), 63-76.

[18]. Nema, A., Modak, P., 1998. A strategic design approach for hazardous waste management systems, Waste management \& Research. 16,210-224.

[19]. Ohri, A., Singh, P. K., 2010. Development of Decision Support System for Municipal Solid Waste Management in India: A Review. International Journal of Environmental Sciences 1(4), 440-453.

[20]. Paily, P., 2006. Optimal siting of solid waste transfer stations for minimizing haul costs, Joint International conference on Computing and Decision making in Civil and Building Engineering, Montreal, Canada (June 14-16).

[21]. Rajendra Kumar Kaushal, George K. Varghese, Mayuri Chabukdhara. 2012. Municipal solid waste management in India- current state and future challenges: a review. International journal of Engineering Science and Technology. 4(4), 1473-1488.

[22]. Rodionov Mikhail, and Nakata Toshihiko, 2011. Design of an optimal waste utilization system: a case study in St. Petersburg, Russia. Sustainability. 3,1486-1509.

[23]. Rogoff, M.J., Liluquist, R.E., Ross, D., Wood, J.L., 2010. Automated Waste Collection - How to make sure it makes sense for your Community, Proceedings of SWANA Waste Conference, USA (August).

[24]. Sarika Rathi, 2007. Optimization model for integrated municipal solid waste management in Mumbai, India, Environment and Development Economics. 12, $105-122$.

[25]. United Nations Environment Program (UNEP), (2013). Taking the pulse of the planet: connecting science with policy. UNEP Global Environment Alert service (GEAS), website: www.unep.org/geas.

[26]. United nations Human Settlement Program (UN-HABITAT), 2010. Collection of Municipal solid Waste in developing Countries, United Nations Publications.

[27]. United nations Human Settlement Program (UN-HABITAT), 2010. Comparing solid Waste Management in the World's Cities. United Nations Publications.

[28]. United States Environmental Protection agency (USEPA), 1977. WRAP: A Model for Solid Waste Management Planning User's Guide (EPA/530/SW-574) US Environmental Protection Agency Ohio, USA.

[29]. Yeomans Julian Scott, 2007. Solid waste planning under uncertainty using evolutionary simulation-optimization. Socio-Economic Planning Sciences 41, 38-60. 